\title{
editorial
}

\section{What's wrong with gender archaeology?}

Nothing of course. Gender archaeology is at the moment one of the healthiest and most thriving fields within the discipline. All major conferences schedule at least one session on the theme; books, particularly edited volumes resulting from such conferences, appear incessantly; critical histories of archaeology stress the impact of women in our disciplinary past; the SAA's Committee on the Status of Women in Archaeology lobbies for a fairer female representation in the profession; etcetera. The list could be expanded ad infinitum. In their impressive reader on contemporary theoretical archaeology, Robert Preucel and Ian Hodder called gender archaeology 'one of the most significant theoretical developments in recent years' $(1996,425)$ and consequently spent considerable pages on it. The even more recent appearance of a Routledge reader strictly confined to gender archaeology (Whitley and Hayes-Gilpin 1998) suggests the final acceptance and institutionalization of the subject within the discipline. Now that gender is increasingly becoming part of the undergraduate curriculum, archaeology finally catches up with the other social sciences where gender has long been on the agenda. After a slow start in the mid-1980s, it has gained so much momentum in the last five years that it has become one of the most vital branches of contemporary archaeology. Once devoted to the sole ambition of making women visible in the past - prehistoric or academic - gender archaeology has now evolved into a rich, varied and expanding field of research.

And yet there is reason for some concern. The mirror-side of the above success story became clear in our own editorial experiences. Since Archaeological Dialogues started to appear five years ago, several manuscripts focusing on aspects of gender archaeology were submitted. As always, we forwarded these for advice and comments to two external and anonymous referees - scholars chosen on the base of not just affinity but also critical distance to the theme discussed. In case of a gender paper, for example, we would send it to someone explicitly working from a gender perspective and to someone more familiar with the substantial part of the work. In general, referee reports - which consist of a filled-in questionnaire and a one-page commentary - converge considerably and facilitate the decision as to whether or not a paper should be published. Not so with the gender papers: the copy sent off to a gender person would almost invariably return with the box that says 'yes, publish in its present form' ticked on the evaluation form. The copy sent to the non-gender referee mostly came back with lesser degrees of enthusiasm. The editorial rule of thumb that 'if two referees are divided, you should ask a third one' was hardly ever of any help: if the third one came from a gender background, the answer could be predicted; if he or she didn't, it was much the same. It might just be the case that all gender manuscripts we received so far were inciden- 
tally stronger on gender issues than on their specific archaeological themes, but I am afraid our experience reveals a more general pattern. It gives the uneasy impression that gender archaeology proclaims itself as a new orthodoxy which welcomes everyone who participates in the language game; the intention of the author being more important than the quality of the paper. It also gives the uneasy impression that mainstream archaeology still is particularly reluctant to genuinely engage with the gender debate and to appreciate its contributions. Of course, such diversity of opinion could be embraced as a healthy sign of pluralism. Yet we're not talking about pluralism here, we're talking about polarization. And this is always to be regretted.

As a result of this polarization a double circuit has emerged within archaeological publishing. On the one hand, there is a very rapidly growing body of gender literature where authors quote and cite each other's work in a sometimes quasi-sectarian fashion. On the other hand, there is the traditional bulk of academic publishing where people act numb when it comes to appraising gender issues. Gender archaeology has been rarely debated in public: either you buy it and get accepted, or you deny it and content yourself with an outcast position. True, there has been some interest, mostly from male postprocessualists, in the arguments from gender and feminist archaeologists. I remember a paper at TAG some years ago entitled 'On the awful dilemma of being bloke and liking feminist theory' (a title which was even more funny after it became clear that there was no irony in it). But in general, the fact that gender archaeology is rapidly growing should not be seen as evidence that it is spreading over other areas of archaeology; it is more like a balloon blown up under water than an ink colouring that water.

What could be the reason for this polarized situation and double publishing circuit? In answering this question, it is too easy to sympathize with one of the two sides and forget the other one. Non-gender archaeologists reproach the sequestered nature of gender studies and claim that it shouldn't be an autonomous field. Gender archaeologists have often interpreted the reluctance to deal with their challenge as the classical, conservative reaction of the largely androcentric academe. It is rather amusing to behold this game of mutual criticism for a while, but in the long run it tends to get boring and sterile. Rather than choosing sides for one of the players, it is useful to wonder whether such strong polarization has ever occurred before in archaeology.

In fact, it has. Much of what we see happening now reminds us of a situation in the early sixties when the New Archaeology was born. If the angry young men of the Midwest can be compared with the gender archaeologists of today, the conservative criticism raised against the former closely parallels the reluctance and implicit rejection of gender studies nowadays. Like now, critics of early processualism argued that there was too much jargon, too much theoretical waffling and far more overlap between the so-called 'new' perspective and the existing paradigm. To no avail: New Archaeologists, like gender archaeologists, constructed a niche of their own claiming that what they did was really different and constituted a radical rupture with what preceded. Although all this was rather arrogant in the absence of any convincing studies, processual archaeology became a serious and noteworthy alternative by the late sixties and early seventies when substantial work demonstrated that this was indeed rather different and promising. It was not Binford's 'Archaeology as anthropology' paper, written 
during an overnight boost of anger and energy in 1962, which changed the outlook of archaeology (no matter how often textbooks cite it as a milestone); it was the Binfords' reinterpretation of Mousterian facies and the substantial work by Flannery and Clarke which did. Only then did processual archaeology establish itself as a something to be reckoned with.

In gender archaeology much ink has been spilled on conceptual issues but regrettably little on 'real' archaeological themes. Sure, in historical perspective it was important first to indicate male bias in much archaeological writing, to appreciate the role of female scholars in the history of archaeology, to hint at the centrality of women in prehistory and to establish a rough outline of gender theory. But after all this has been said and done ad nauseam, one would really like to see how such gender perspective genuinely enhances and enriches our understanding of the past - assuming at least that such understanding is still one of archaeology's major ambitions even in a feminized age. This is where gender archaeology has been frankly disappointing hitherto. If gender archaeology is indeed 'one of the most significant theoretical developments in recent years', one hopes that it won't remain just a theoretical development. Granted that conceptual reflection needs to be pursued (as Knapp and Meskell undertake on the subsequent pages), gender archaeology would unduly atrophy itself if it became restricted to it. Both papers do not intend to solve all problems gender archaeology runs into, but they and especially the discussion following Knapp's contribution might help to identify some of the basic difficulties outlined above.

Thus far, Roberta Gilchrist's Gender and Material Culture: The Archaeology of Religious Women (1994) is still the best, and perhaps even the only, example of how such 'applied' gender archaeology might look like. The combination of her research interest in medieval monasticism and her commitment to feminism has led her to explore the much understudied and misunderstood place of nunneries in medieval Britain. Rather than female replicas of the well-known male communities, she found that nunneries had a distinct origin (more related to the local gentry than to international orders), a distinct place in the landscape (placed in isolated settings but more dependent on the outside world than male communities), and a distinct material culture (cloisters are more akin to gentry houses which could expand organically rather than obeying to some religious architectural canon). More than anything else, Gilchrist's work has shown that gender archaeology is not about new data or new methods, nor even about new theories (her conceptual framework essentially goes back to the mid-1980s work of Ian Hodder and Henrietta Moore), but about new questions. What distinguishes her work from others is that she has not only posed these questions but has gone a considerable way in trying to answer them. If gender archaeology really wants to gain the credits it deserves, it will have to start answering the questions which it asked fifteen years ago and have remained unaltered, but too often repeated since. (DVR) 